\title{
Cosmetic Stay-green Trait in Snap Bean and the Event Cascade That Reduces Seed Germination and Emergence
}

\author{
Melike Cirak and James R. Myers \\ Department of Horticulture, Oregon State University, Corvallis, OR 97331
}

\begin{abstract}
AdDitional INDEX wORDs. common bean, persistent color, Phaseolus vulgaris, seed anatomy
Abstract. The persistent color (pc) trait in snap bean (Phaseolus vulgaris L.) is a member of the stay-green gene family and falls into the cosmetic subclass. Cosmetic stay-green variants remain green but lose photosynthetic competence during senescence. It is an economically useful trait in snap bean as a result of its effects on pod quality. The trait produces a dark-green, uniform appearance of fresh pods, but has other pleiotropic effects, including a light-green seed color, bleached-white cotyledons on emergence, and foliage and pods that remain green even while senescing. One additional pleiotropic effect is reduced field germination and emergence compared with white- and coloredseeded genotypes. Nevertheless, with the aid of seed-applied fungicides, $p c$ types occupy $\approx \mathbf{4 0} \%$ of commercial snap bean acreage in the United States. This research project was aimed at understanding why and how germination and emergence is affected in $p c$ beans. The effect is thought to be related to soil-borne pathogens because fungicide treatment of $p c$ seeds increases germination and emergence rates to levels comparable to treated white- and coloredseeded genotypes. For our experiments, we increased seeds of 45 experimental lines and commercial cultivars (25 of which were $p c$ ) under uniform growing conditions. Initial experiments documented that, in the laboratory, all seeds analyzed in a tetrazolium test had high viability. Furthermore, untreated seeds of $p c$ and non-pc types germinated in the laboratory showed no difference in germinability, whereas in the field, germination of $p c$ types was reduced significantly. In addition, $p c$ types showed substantially greater infection rates of seeds and seedlings, with the main pathogen being Fusarium oxysporum Schl. f. sp. phaseoli Kendrick \& Snyder. Water uptake by green pc seeds was significantly more rapid than white and colored seeds. Measurements of electrical conductivity revealed that $p c$ types had greater solute leakage than other seed types. When seed anatomic structure was examined, $p c$ types had a significantly thinner testa, especially the osteosclereid layer. The reduction in germination and emergence appears to begin with a thinner, more fragile testa showing increased cracking that may happen during seed harvest and conditioning (but certainly does happen during imbibition), allowing more rapid water uptake during germination that leads to testa rupture. Increased and rapid solute diffusion into the surrounding spermosphere stimulates and attracts pathogens to colonize the seeds before seedlings can become established. Seed handling and conditioning processes before planting could be modified to improve field emergence and stand establishment. Selection for thicker testa may also mitigate some of the damage observed during germination of $p c$ cultivars.
\end{abstract}

Snap bean (Phaseolus vulgaris), the vegetable form of the common bean, is an important crop globally, with production of more than 1.8 million Mg in 2018 (Food and Agriculture Organization of the United Nations, 2021). In the United States, the total value of snap beans in 2019 was $\$ 303.5$ million (U.S. Department of Agriculture, National Agricultural Statistics Service, 2020). Currently, flavonoid-free cultivars are required for processing because water-soluble compounds in colored bean seeds and pods may leach and color the liquid in canned beans, and appear as a colored ring in frozen cut pods, making them undesirable for processing (Myers and Baggett, 1999). The recessive gene pigment $(p)$ is used by snap bean breeders to

Received for publication 4 Jan. 2021. Accepted for publication 3 Apr. 2021. Published online 14 June 2021.

M.C. was supported by a graduate research assistantship from the Turkish Ministry of Education in support of an MS degree. This study was supported in part by the U.S. Department of Agriculture, National Institute of Food and Agriculture W3150 multistate project and the Oregon State University Baggett-Frazier Endowment.

We gratefully acknowledge Sabry Elias and Kathy Cook for assistance with seed physiology and anatomy studies.

J.R.M. is the corresponding author. E-mail: james.myers@oregonstate.edu. This is an open access article distributed under the CC BY-NC-ND license (https://creativecommons.org/licenses/by-nc-nd/4.0/). produce white seeds (Myers and Baggett, 1999); it also eliminates flavonoids pleiotropically from flowers, pods, and vegetative tissues as well as the seeds (Bassett, 2007). In the field, white seed color is associated with greater imbibitional cracking, and reduced germination and emergence compared with colored-seed beans, and virtually all seeds for commercial planting in nonorganic production are treated with fungicides. Some snap bean cultivars used for the fresh market, for which the pod quality standards are not as stringent, may have colored seeds.

Another seedcoat color type being used in snap bean is persistent color $(p c)$, with $\approx 40 \%$ of snap bean acreage in the United States planted to cultivars with this trait (Myers et al., 2018). This gene is used in combination with $p$ such that most $p c$ snap beans also lack flavonoids. Snap beans with $p c$ are considered desirable because the trait imparts a very uniform, dark-green pod color. Other pleiotropic effects of $p c$ include pale-green mature seed color when plants are homozygous recessive at the $p$ locus; white (bleached) rather than green cotyledons upon emergence; and foliage, stems, and pods that remain green upon senescence (Bouwkamp and Honma, 1970; Dean, 1968; Myers et al., 2018). One negative characteristic of $p c$ is that cultivars with the trait have reduced germination and emergence rates in the field compared with both white- and colored-seeded 
genotypes (Al-Jadi et al., 2016). Fungicide treatment of $p c$ seeds increases germination and emergence to where rates are essentially equivalent to fungicide-treated white-seeded beans (AlJadi et al., 2016); therefore, soil-borne pathogens seem to be involved in this process, but what underlies the apparent greater vulnerability to pathogens is unknown.

Persistent color is a member of the stay-green gene family (Davis et al., 2009), which has been identified as economically important in several crop species (Myers et al., 2018). Mutations for stay-green are generally classed into either functional or cosmetic types. In functional stay-green, photosynthesis continues for a longer than normal period in plants (Thomas and Smart, 1993). Functional stay-green has been used in field crops to increase yields and provide greater abiotic stress tolerance (Myers et al., 2018). In contrast, cosmetic stay-green interrupts chlorophyll catabolism during senescence, but photosynthetic competence is lost (Thomas and Howarth, 2000). Plant vegetative and reproductive organs remain green even as moisture is lost from the tissues. Cosmetic stay-green has not been shown to have the same positive effect on productivity and stress tolerance found for functional stay-green, but it has been valued especially in horticultural crops for its positive effects on quality and, more generally, as a tool to understanding the photosynthetic process and chloroplast catabolism pathway (Myers et al., 2018).

The objective of our research was to understand the deleterious effects conferred by $p c$ on germination and emergence rates in snap beans. A series of experiments was conducted to compare $p c$ genotypes to white- and colored-seeded counterparts in terms of laboratory and field performance as well as to analyze seed physiological and anatomic characteristics.

\section{Materials and Methods}

Plant materials. Seeds of 45 snap bean breeding lines and commercial cultivars (Supplemental Table 1) were increased in the greenhouse, followed by an increase in the field to obtained seed lots produced under the same growing conditions. These materials represented three seed phenotypes including pale green $(p c)$, white $(p)$, and colored seed (conditioned by several gene combinations; see Supplemental Table 1 for genotypes). After gathering and increasing lines, we found that some were more productive than others and some were isogenic for $p c$, and subsequent experiments following germination tests focused in on a narrower set of lines. In addition to these lines, three other cultivars not included in these increases were used in individual experiments. These were 'Roc D'or' (a black-seeded snap bean), 'OSU5630' (a white-seeded bush blue lake cultivar) and 'Pascal' (a French flageolet type possessing $p c$ ). 'Roc d'Or' and 'OSU5630 ' were included in field tests because the former produced high levels of flavonoids that might prevent microbial infections, and OSU5630 is the predominant bush blue lake green bean used by the processing industry in western Oregon and provided a benchmark for pathogen studies. 'Pascal' was included in anatomic studies so we could compare a flageolet type to snap bean lines with $p c$.

The core set of lines used in experiments was a set of breeding lines that was homozygous for $p$ but near-isogenic for $p c$. The pigment gene is located on $\mathrm{Pv} 07$ whereas persistent color segregates independently and is found on $\mathrm{Pv} 02$. The pairs of 'OSU6504', 'OSU6510-4', and 'OSU6523' were developed by pedigree selection to $\mathrm{F}_{6}$, then propagating by massing by line for another six generations, after which individual plants with either $p p P c P c$ or $p p p c p c$ were selected and increased. The 'Flamata' pair was observed in a bulk seed lot of the cultivar, and the two types were propagated to verify they showed no segregation. Another pair of lines used in experiments, 'Spartacus' ( $p p p c p c)$ and 'Ulysses' ( $p p P c P c$ ), developed by Seminis Seed Co. (St. Louis, MO) are sister lines that share a genetic background but differ at the $P c$ locus (K.A. Kmieck, personal communication). 'OR91G' is a white-seeded $(p P c)$ bush blue lake green bean developed originally by the Oregon State University (OSU) snap bean breeding program for commercial production and processing in western Oregon (Baggett et al., 1981). The different seed color versions of 'OR91G' were developed by three backcrosses of the seed testa color genes into the 'OR91G' background. The genotype relevant to this study is the $p^{g r i}$ allele, which is partially functional and allows weak expression of flavonoids conditioned by other genes in the background; in contrast to $p$, which suppresses flavonoid expression, and $P$, which promotes full flavonoid expression. Further information on the 'OR91G' genotypes is found in the footnote to Supplemental Table 1.

Evaluation of SEED viability by TETRAZOlium assay. Our preliminary examination included a tetrazolium test to evaluate maximum potential germination of seeds (Patil and Dadlani, 1993). The analysis was conducted with 10 lines corresponding to five near-isogenic pairs - 'OSU6523- $p p c$ '-'OSU6523- $p P c$ ', 'OSU6510-4- $p$ pc'-'OSU6510-4- $p$ Pc', 'Flamata- $p \quad p c$ '-'Flamata- $p$ Pc', 'Spartacus' $(p p c)$, and 'Ulysses' $(p P c)$-for the comparison of white and persistent color genotypes, and 'OR91G- $p P c^{\prime}$ ' (white) and 'OR1G- $p^{g r i} P c^{\prime}$ ' (colored) for whiteseeded and colored-seeded genotypes.

One hundred seeds divided into two replicates per genotype were hydrated with tap water overnight at $22^{\circ} \mathrm{C}$. Seeds were cut in half; the halves with the embryo were incubated in $1 \mathrm{mg} \cdot \mathrm{L}^{-1}$ tetrazolium chloride solution in a growth chamber at $30^{\circ} \mathrm{C}$ overnight. Seeds were evaluated for the presence or absence of red pigmentation formed when live cells catalyze tetrazolium chloride to formazan (Patil and Dadlani, 1993). Seeds remaining white, grayish, blurred, pale-red or pink were classified as nonviable and nongerminable (Patil and Dadlani, 1993).

Germination without the PRESENCE OF SOIL-BORNE PATHOGENS. A total of 39 genotypes (Supplemental Table 1) were germinated using two replications of 25 seeds each and repeated twice (runs). The experiment was conducted as a randomized complete block design, with reps nested within runs. Germination was carried out in paper towel rolls moistened with deionized water and placed in plastic boxes to maintain humidity. Boxes were held at ambient laboratory temperature $\left(22^{\circ} \mathrm{C}\right)$ for up to 1 week, with water added as needed. Seeds were rated for percent germination, whether the seed had an endogenous infection (measured as a percentage), and whether the seed failed to imbibe (measured as a percentage of hard seed).

Field GERmination AND EMERGENCE TESTS. Forty-four lines and cultivars from the greenhouse harvest were evaluated in a field emergence test. The seeds were split into two lots and one lot was treated with Captan fungicide (Bonide Products LLC, Oriskany, NY). Experimental design was a randomized complete block design, with genotype and fungicide treatment as main effects. Depending on seed availability, two or four replicates with 30 seeds per plot were planted at a depth of $3 \mathrm{~cm}$ using a hand-pushed belt planter on 15 June 2018 into a Chehalis silt loam soil (fine-silty, mixed, superactive, mesic Cumulic Ultic 
Haploxeroll) at the OSU Vegetable Research Farm, Corvallis, OR (lat. $44^{\circ} 34^{\prime} 25.6^{\prime \prime} \mathrm{N}$, long. $123^{\circ} 14^{\prime} 12.3^{\prime \prime} \mathrm{W}$ ). Soil temperatures at the time were warm: $21^{\circ} \mathrm{C}$ at a $5-\mathrm{cm}$ soil depth. Data were collected on total emergence and the number of normal and abnormal seedlings $\approx 2$ weeks after planting. Data were converted to percentages for analysis.

Evaluation OF PATHOGENS REDUCING GERMinAtion IN THE FIELD. In the first experiment, untreated seeds from $p c$ cultivar Castano were planted in the same location as that of the germination trial on 11 July 2018 to identify potential pathogens of germinating seeds. 'Castano' was used for this experiment because we had the largest quantity of seeds for this cultivar available for field experiments. Two hundred seeds were planted (as described in the previous section) in a 4-m row. Beginning $5 \mathrm{~d}$ after planting and repeated four times at 2- or 3-d intervals, $1 \mathrm{~m}$ of each row was excavated and the soil sieved through a 6-mm mesh to recover seeds, seedlings, and seed fragments. The seeds and seed fragments were washed and dried gently before grading for disease symptoms. Representative samples with necrotic lesions were sent to the OSU Plant Disease Clinic for pathogen identification. The experiment was repeated with three cultivars: Castano ( $p c)$, Roc d'Or (colored), and OR5630 (white). Thirty seeds from each line were planted on 13 Aug. 2018 and a similar procedure to the first experiment was performed to collect the data.

WATER UPTAKE EXPERIMENT. Rate of water uptake among seed types was measured using three isogenic pairs: 'OSU6523$p$ Pc'-'OSU6523- $p$ pc', 'Ulysses' ( $p$ Pc)-'Spartacus' ( $p p c)$, and 'OR91G- $p$ Pc'-'OR1G- $p^{g r i} P c^{\prime}$ '. The first two pairs provided a contrast at the $p c$ locus whereas the third pair compared white to colored seeds.

The experiment was conducted as a randomized complete block design. Forty seeds in four replicates of 10 seeds each that were intact and showed no visible damage were weighed and placed in glass beakers. Twenty-five milliliters of distilled water was added, and the seeds were allowed to imbibe at $22^{\circ} \mathrm{C}$. Subsequently, the seeds were weighed six times at 90-min intervals during imbibition. Before weighing, seeds were drained then blotted dry. After weighing, seeds were placed back in the beakers and additional water was added. After water uptake analysis, the imbibed seeds were dried; seed lots were examined for hard seed, and testa of individual seeds was observed for cracks.

EleCtRICAL CONDUCTIVITY AND MOISTURE. The isogenic pairs were compared for electrical conductivity (EC) to quantify solute leakage of different seed types. Two pairs that were near isogenic for $p c$ ('OSU6523- $p \quad p c$ ' vs. 'OSU6523- $p \quad P c$ ' and 'OSU6510-4 $p p c$ ' vs. 'OSU6510-4 p Pc'), the 'Spartacus' ( $p$ $p c$ )-'Ulysses' ( $p$ Pc) pair, and the 'OR91G- $p$ Pc'-'OR1G- $p^{g r i}$ $P c$ ' white- vs. colored-seeded pair were used in this experiment.

Before measuring EC, the seed moisture content of the seed lots was quantified and adjusted as needed. We used the Association of Official Seed Analysts protocol (Smýkal et al., 2014), which consists of grinding seeds to a fine powder, weighing $5 \mathrm{~g}$, drying in an oven at $130^{\circ} \mathrm{C}$ for $1 \mathrm{~h}$, and reweighing. Most seed lots were at $9.5 \%$ moisture, but three genotypes were lower. 'Spartacus', 'Ulysses', and 'OSU6523-p pc' were at 8.1\%, $9.3 \%$, and $9.3 \%$ moisture, respectively. These seed lots were moisturized by placing seeds between sheets of wet germination paper for $60 \mathrm{~min}$ for 'Spartacus' and $30 \mathrm{~min}$ for the other two lines in accordance with sample preparation as specified by International Seed Testing Association Rules, Section 15.8.1.4 (International Seed Testing Association, 2005).
EC was performed using a completely random design, with two replicates of 50 seeds of each line. Seeds without visible damage were chosen. The seeds were weighed and allowed to imbibe in $250 \mathrm{~mL}$ distilled water for $24 \mathrm{~h}$ at $22^{\circ} \mathrm{C}$. After gently shaking the seeds for $10 \mathrm{~s}$, EC was measured using a benchtop conductivity meter (Orion VersaStar; Thermo Fisher Scientific, Waltham, MA). EC was calculated as micro-Siemens per centimeter per gram $=(\mathrm{EC}-$ Background reading $) /$ Weight of replicate (grams) (International Seed Testing Association, 2005).

Seed anatomic structure. The seed testa anatomy, with a focus on the three outer layers of the testa (macrosclereid, osteosclereid, and parenchyma layers), was compared among different seed color genotypes. The first experiment used 'Pascal' $(p p c)$, 'OR91G- $p P c$ ', and 'OR91G-p ${ }^{\text {gri }} P c$ ', representing a $p c$ flageolet type, and white- and colored-seeded genotypes. Dry seeds were cut and pieces from near the embryo were fixed in formalin-acetic acid-alcohol (10\%-50\%-5\%) in a vacuum; dehydrated in a 50\%, $70 \%$, and $95 \%$ ethanol series for 24,24 , and $72 \mathrm{~h}$, respectively; and infiltrated in a $2: 1,1: 1,1: 2$ mixture of $95 \%$ ethanol:plastic infiltration solution (Technovit 7100; Kulzer, Hesse, Germany) for 24, 48, and $72 \mathrm{~h}$, respectively. Samples were fixed in glycol methacrylate plastic (Technovit 7100) and sectioned using a steel knife at 5 to 7 $\mu \mathrm{m}$ on a rotary microtome. Sections were mounted on microscope slides, with at least four slides per genotype, then dried gently $\left(37^{\circ} \mathrm{C}\right.$ for $2 \mathrm{~h}$ ) and stained in $0.5 \%$ toluidine blue $\mathrm{O}$ in citrate buffer $(\mathrm{pH} 4.2)$. The seed testa layers were measured under $400 \times$ magnification using an ocular micrometer. Data for seed testa thickness were collected from 10 sections per genotype. The examination was repeated with additional genotype pairs 'OSU6523- $p$ $p c$ '-'OSU6523- $p$ Pc', 'OSU6510-4- $p$ pc'-'OSU6510-4- $p$ Pc', and 'Spartacus' $(p, p c)$-'Ulysses' $(p P c)$ using the preparation techniques described earlier.

EXPERIMENTAL DESIGN AND STATISTICAL ANALySis. Except as noted earlier, a randomized complete block design was used with two to four replicates. Statistical analysis was performed with SAS (version 9.4; SAS Institute, Cary, NC). Experiments were analyzed in two ways with either genotypes or seed type as a main effect. In the field emergence experiment, fungicide treatment was also included as a main effect. Analysis of variance was conducted using PROC GLM in SAS. If the experimental design was balanced, means were calculated and compared using Fisher's protected least significant difference test. When missing values were present, least-square means were estimated and the pdiff option was used to conduct all pairwise comparisons under the null hypothesis that least-square means were equal. Percentage data were transformed using an arcsine function and, after analysis, was back-transformed for the means reported in the tables.

\section{Results}

Evaluation OF SEED VIABILITY bY TETRAZOLIUM ASSAY. The tetrazolium test revealed relatively high viability for seeds of almost all genotypes. 'OSU6523-p pc' had 3\% hard seeds; two of three seeds proved to be viable. In a second replication, this genotype had no hard seeds. Overall, viability percentages were 99\% for $p c, 99 \%$ for white-seeded, and $98 \%$ for colored-seeded genotypes. There were no significant differences among isogenic pairs.

Germination IN A LABORATORY SETting. The laboratory germination test revealed no significant differences among the seedcoat color types for both runs. The first run had a mean germination of $84 \%$ whereas the second run was significantly 
less at $65 \%$. The second run had greater levels of microbial contamination on seeds that probably reduced germination, but it affected all seed types equally. The least-square means for germination of the three different seed types did not differ at $\alpha=$ 0.05 (Table 1).

Field Germination AND EMERGence Tests. When seed types were compared, no significant differences were observed among white- and colored-seeded types. However, $p c$ types had significantly lower emergence and normal seedlings than other seed types in the same treatment group (Table 1). Fungicide treatment of seeds before planting improved significantly emergence [treated $(81 \%)$ vs. untreated $(75 \%)$ ] and the percentage of normal seedlings [treated $(71 \%)$ vs. untreated $(65 \%)$ ]. Untreated seeds had a significantly lower percent emergence and normal seedlings than fungicide-treated seeds in each seed color category (Table 2), and untreated $p c$ seed had the worst performance. Mean emergence and normal seedling percentages of treated $p c$ seeds were equivalent to untreated white and colored seeds. Significant and sizable differences were observed among treated and untreated seeds for certain $p c$ lines: 'Castano' showed a differential of $40 \%$; 'Flaveol', 63\%; 'Flagrano', 37\%; and 'Hystyle', 24\% (data not shown).

Evaluation OF PATHOGENS REDUCING GERMINATION IN THE FIELD. For the first experiment, only a single $p c$ cultivar was examined. From a total of 200 seeds planted of the $p c$ cultivar Castano, 64 seeds and seedlings (32\%) were recovered from the field. These were categorized as 1) uninfected and germinating seeds; 2) infected and germinating seeds; and 3) infected, ungerminated, or dead seed. Forty-two percent of recovered seeds and seedlings were normal, but $57 \%$ showed signs of infection. From samples sent to the OSU Plant Disease Diagnostic Clinic, Fusarium oxysporum f. sp. phaseoli was isolated from lesions on hypocotyls and cotyledons. Of the seeds showing infection, 34\% had germinated, whereas the remaining $23 \%$ showed signs of imbibition but no germination, and often were rotting fragments. This experiment also revealed statistically significantly $(P=0.04)$ greater hypocotyl length $(7.0 \mathrm{vs} .4 .8 \mathrm{~cm})$ of pathogen-free seedlings compared with infected seedlings. As might be expected with

Table 1. Least square means for different snap bean seed color types for germination in the laboratory and emergence and normal seedling development in the field at the Oregon State University Vegetable Research Farm, Corvallis, OR.

\begin{tabular}{lccc}
\hline & \multirow{2}{*}{$\begin{array}{c}\text { Laboratory, } \\
\text { Seed type }\end{array}$} & \multicolumn{2}{c}{ Field $(\%)^{\mathrm{y}}$} \\
\cline { 3 - 4 } & germination $(\%)^{\mathrm{z}}$ & Emergence & Normal seedling ${ }^{\mathrm{x}}$ \\
\hline White $(p)$ & $73.4 \mathrm{a}^{\mathrm{w}}$ & $80.2 \mathrm{a}$ & $71.3 \mathrm{a}$ \\
Colored $^{\mathrm{v}}$ & $73.5 \mathrm{a}$ & $80.4 \mathrm{a}$ & $70.4 \mathrm{a}$ \\
Green $(p c)$ & $74.9 \mathrm{a}$ & $73.8 \mathrm{~b}$ & $63.2 \mathrm{~b}$ \\
\hline
\end{tabular}

${ }^{\mathrm{z}}$ Based on the average of four reps (two reps repeated two times).

${ }^{\mathrm{y}}$ Means for the seed classes are an average of treated and untreated seeds.

${ }^{\mathrm{x}}$ Normal seedlings are well-developed, healthy seedlings with most seedcoats shed from the cotyledons and not missing any essential seedling structures.

${ }^{\mathrm{w}}$ Means followed by the same letter in a column are not significantly different at $P \leq 0.05$ as determined by Fisher's protected least significant difference.

${ }^{\mathrm{v}}$ Colored seeds have various flavonoid pigments. See Supplemental Table 1 for details.

$p=$ plant parts not pigmented; $p c=$ leaves and stems remain green at senescence; dry seeds are pale green and cotyledons of emerging seedlings are bleached white.
Table 2. Interaction of seed type and fungicide treatment and its effect on percentage of normal seedlings and emergence of snap bean lines grown in the field at the Oregon State University Vegetable Research Farm, Corvallis, OR.

\begin{tabular}{llcrcc}
\hline & \multicolumn{2}{c}{ Emergence (\%) } & & \multicolumn{2}{c}{ Normal seedlings (\%) } \\
\cline { 2 - 3 } \cline { 5 - 6 } Seed type & Treated & Untreated & & Treated & Untreated \\
\hline White $(p)$ & $81.6 \mathrm{a}^{\mathrm{z}}$ & $78.8 \mathrm{~b}$ & & $73.7 \mathrm{a}$ & $68.9 \mathrm{~b}$ \\
Colored & $84.4 \mathrm{a}$ & $76.3 \mathrm{~b}$ & & $75.2 \mathrm{a}$ & $65.6 \mathrm{~b}$ \\
Green $(p c)$ & $78.2 \mathrm{~b}$ & $69.3 \mathrm{c}$ & & $66.8 \mathrm{~b}$ & $59.5 \mathrm{c}$ \\
\hline
\end{tabular}

${ }^{\mathrm{z}}$ Means followed by the same letter for a seedling parameter are not significantly different at $P \leq 0.05$ as determined by Fisher's protected least significant difference.

${ }^{\mathrm{y}}$ Colored seeds have various flavonoid pigments. See Supplemental Table 1 for a description of seed types.

$p=$ plant parts not pigmented; $p c=$ leaves and stems remain green at senescence; dry seeds are pale green and cotyledons of emerging seedlings are bleached white.

differences in hypocotyl length, infected seedlings were slower to emerge, which was more noticeable in the second week.

We modified the second experiment to compare 'Castano' $(p c)$ with other seed types. The comparison produced similar results for 'Castano' for seedling infections and hypocotyl length. Infection rates were lower for 'OSU5630' and 'Roc d'Or' compared with 'Castano' (Fig. 1). The percentage of recovered seeds was $63 \%$ for 'Castano', $80 \%$ for 'OSU5630', and 63\% 'Roc d'Or'. The lower rate of recovery of 'Roc d'Or' seeds may have been related to the low contrast between their seed color and the soil color. Germination percentages of normal seedlings for 'Castano', 'OSU5630', and 'Roc d'Or' were 58\%, 96\%, and $79 \%$, respectively (Fig. 1). 'Castano' seedlings had reduced vigor compared with the other seed types, suggesting a slower germination rate beyond what might have been caused by pathogen infection.

WATER UPTAKE EXPERIMENT. White- and green-seeded $(p c)$ pairs showed differences in rate of imbibition (Fig. 2A and B). Rate of uptake was more rapid for $p c$ genotypes, especially in the exponential phase of the curve. The sister line pair 'Spartacus'-'Ulysses' had essentially the same initial seed weight ( $3.4 \mathrm{~g} / 10$ seed), but showed significant differences in seed weight for time points of 180 to $360 \mathrm{~min}$. Thereafter, and as long as $540 \mathrm{~min}$, seed weights converged. During the exponential phase, imbibition was more rapid for the $p c$ line ('Spartacus'). The near-isogenic pair 'OSU6523- $p$ $p c$ ' (green)-'OSU6523- $p$ Pc' (white) had similar but not identical weights of $2.3 \mathrm{~g} / 10$ seed (white) and $2.5 \mathrm{~g} \mathrm{10/seed} \mathrm{(green).}$ 'OSU6523- $p p c$ ' showed a significantly greater weight gain in the first $90 \mathrm{~min}$, whereupon the slope of lines between time points became essentially parallel and the weight differential established at 90 min carried through the rest of our experiment. 'OR91G- $p$ Pc' (white) and 'OR91G- $p^{g r i} P c^{\prime}$ ' (colored) near-isogenic lines had different-size seed, with a dry weight of $2.8 \mathrm{~g} / 10$ seed (white) vs. 3.5 $\mathrm{g} / 10$ seed (colored), and this difference carried through during imbibition. Although the placement of the curves was different, the slopes of the lines between time points did not show significant differences (Fig. 2C).

After imbibition, the blotted dry seeds were sorted into the categories of seeds with cracked testa vs. those with intact testa. 'OR91G- $p$ P $c$ ' had significantly more cracked testas (43\%) than its colored seed counterpart 'OR91G- $p^{g r i} P c^{\prime}$ ' $(8 \%, P \leq 0.01)$. The $p c$ seeds had about two times as many cracked testas as their white-seeded counterparts, and the difference was highly 


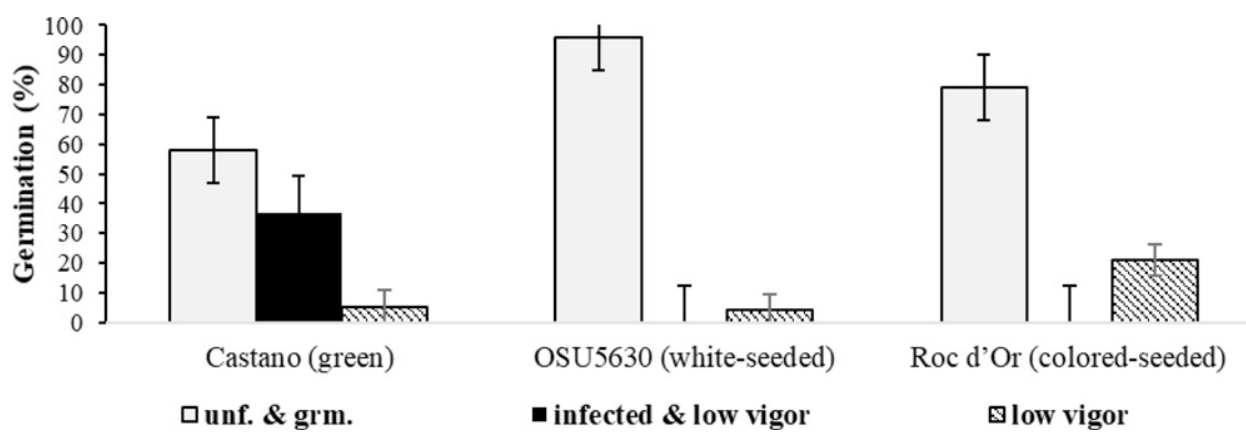

Fig. 1. Comparison of seed germination without fungicide treatment for green $(p p c)$, white $\left(p P_{c}\right)$ and coloredseeded $\left(P P_{c}\right)$ snap bean genotypes grown at the Oregon State University Vegetable Research Farm, Corvallis, OR, in 2018. $p$, plant parts not pigmented; $p c$, leaves and stems remain green at senescence, and dry seeds are pale green and cotyledons of emerging seedlings are bleached white; $P c$, plant parts show normal expression; unf. \& grm, uninfected and germinated seeds. Colored seeds have various flavonoid pigments. See Supplemental Table 1 for details.

statistically significant $(P \leq 0.002)$. For the Seminis pair, 'Spartacus' $(p p c)$ had 70\% cracking whereas 'Ulysses' $(p P c)$ had $38 \%$ ( $P \leq 0.007)$. In a similar manner, 'OSU6523- $p$ pc' had $18 \%$ cracking whereas its white-seeded counterpart had $10 \%$, but the difference was not statistically significant.

Electrical Conductivity. The greatest electrolyte leakage was recorded for $p c$ genotypes $\left(37.7 \mu \mathrm{S} \cdot \mathrm{cm}^{-1} \cdot \mathrm{g}^{-1}\right)$. White-seeded types were intermediate $\left(28.0 \mu \mathrm{S} \cdot \mathrm{cm}^{-1} \cdot \mathrm{g}^{-1}\right)$, and colored-seeded genotypes were lowest at $18.7 \mu \mathrm{S} \cdot \mathrm{cm}^{-1} \cdot \mathrm{g}^{-1}$. The $p c$ EC was significantly greater than white- $(P=0.02)$ and colored-seeded $(P=$ $0.009)$ lines, but white- and colored-seeded means were not significantly different from one another $(P=0.08)$. When comparing near-isogenic pairs, the $p c$ genotype always had a greater EC than its white-seeded counterpart (Fig. 3). 'OR91G' white seeds had a greater EC than its colored-seeded counterpart. Among pairs, the greatest differential was observed for the 'OSU6523' pair.

SeEd Testa Anatomic structure. A micrograph displaying the layers of the seed testa examined in this study is shown in Fig. 4. In the first study of seed testa anatomy, 'Pascal' $(p c)$, 'OR91G- $p$ Pc', and 'OR91G $p^{g r i} P c^{\prime}$ ' were compared. All three layers examined were thinner in 'Pascal' than in other lines, but the greatest differences were observed in the osteosclereid layer (Fig. 5). For total testa thickness (sum of the three layers) 'Pascal' was thinnest at $31.6 \mu \mathrm{m}$, 'OR91G- $p P c$ ' was $69.0 \mu \mathrm{m}$, and 'OR91G $p^{\text {gri }} P c^{\prime}$ ' was $54.7 \mu \mathrm{m}$. Because genotypes with different genetic backgrounds were used in the first study, we repeated the anatomic comparison using near-isogenic pairs. The results were nearly identical, with $p c$ types having a significantly thinner osteosclereid layer (mean, $8.5 \mu \mathrm{m}$ ) across lines compared with more than $12.0 \mu \mathrm{m}$ in non- $p c$ seeds (Fig. 6). Macrosclereid and parenchyma layers were also thinner in $p c$ types. Although differences were statistically significant, they were not as pronounced as in the first experiment. The pairwise comparisons among near-isogenic lines for osteosclereid layer and total testa revealed a differential of $4.9 \mu \mathrm{m}$ and $8.0 \mu \mathrm{m}$ for 'OSU6523' and 'OSU6510-4', respectively (Fig. 7).

\section{Discussion}

Three factors were key to conducting these experiments. One was the use of seed that had been grown under the same environmental conditions to eliminate any potential variation induced by differences in production environment. Second was to hand-harvest seed and to handle it gently during threshing, cleaning, and conditioning to eliminate the potential for differences in mechanical damage that might cause variation in response to treatments. Third was the use of near-isogenic lines for seedcoat color in these experiments. This allowed us to see differences in response to treatments unaffected by genetic background. Because these three factors reduced environmental and genetic variation, we were able to see clear differences among seed types.

Al-Jadi et al. (2016) was the first to study and report germination issues with $p c$ beans. Results from our study corroborate the previous study (Al-Jadi et al., 2016) that $p c$ snap beans have reduced germination and emergence in the field, and that the application of fungicide to the seeds before planting boosts emergence to levels similar to white-seeded snap beans. We expanded on the research of Al-Jadi et al. (2016) to understand the underlying causes of the phenomenon. Such a finding implies that soil-borne pathogens are colonizing germinating seeds and are causing infections that are potentially lethal to developing seedlings. In our study, the differential between genotypes and fungicide treatments was relatively small compared with that found by Al-Jadi et al. (2016), but this may have been the result of planting in warmer soils when conditions were more favorable for bean seed germination.

The question becomes: why do $p c$ seeds seem to be prone to pathogen attack that limits germination and emergence under field conditions? A possibility is that $p c$ affects seed traits that are involved in germination, which affects the seedling response to pathogens. Several pleiotropic effects are already knownfrom the persistent green foliage, to pale-green seed color, to the bleached cotyledons during germination - and it is possible there are others.

A seed consists of an embryo and stored nutrients encased in a seedcoat or testa (Mauseth, 1988), and when seeds begin imbibition in the soil, these nutrients and embryo are protected from pathogen attack by the testa. During imbibition, the testa may participate in the control of water movement into the seed as well as diffusion of seed solutes into the soil. With diffusion of solutes, pathogenic fungi may proliferate in the spermosphere and colonize the developing seedling (Halloin, 1986; Mayne et al., 1969; Mohamed-Yasseen, 1991; Mohamed-Yasseen et al., 1991). Seeds normally exhibit a burst of solutes released during early phases of imbibition, but this tapers off quickly. However, damage to the embryo and physical breaks in the testa may increase duration, rate, and volume of diffusion. This has been documented in onion (Allium cepa L.) seeds, in which scarification increased electrolyte leakage, increased fungal infection, and reduced germination rates (Mohamed-Yasseen and Splittstoesser, 1991; Splittstoesser et al., 1994).

Compared with other seed types, $p c$ seeds imbibe more rapidly (Fig. 2) and show more cracking of the testa. They have greater leakage of solutes, as demonstrated by a greater EC (Fig. 3). We did not examine when solute leakage began, but greater levels 

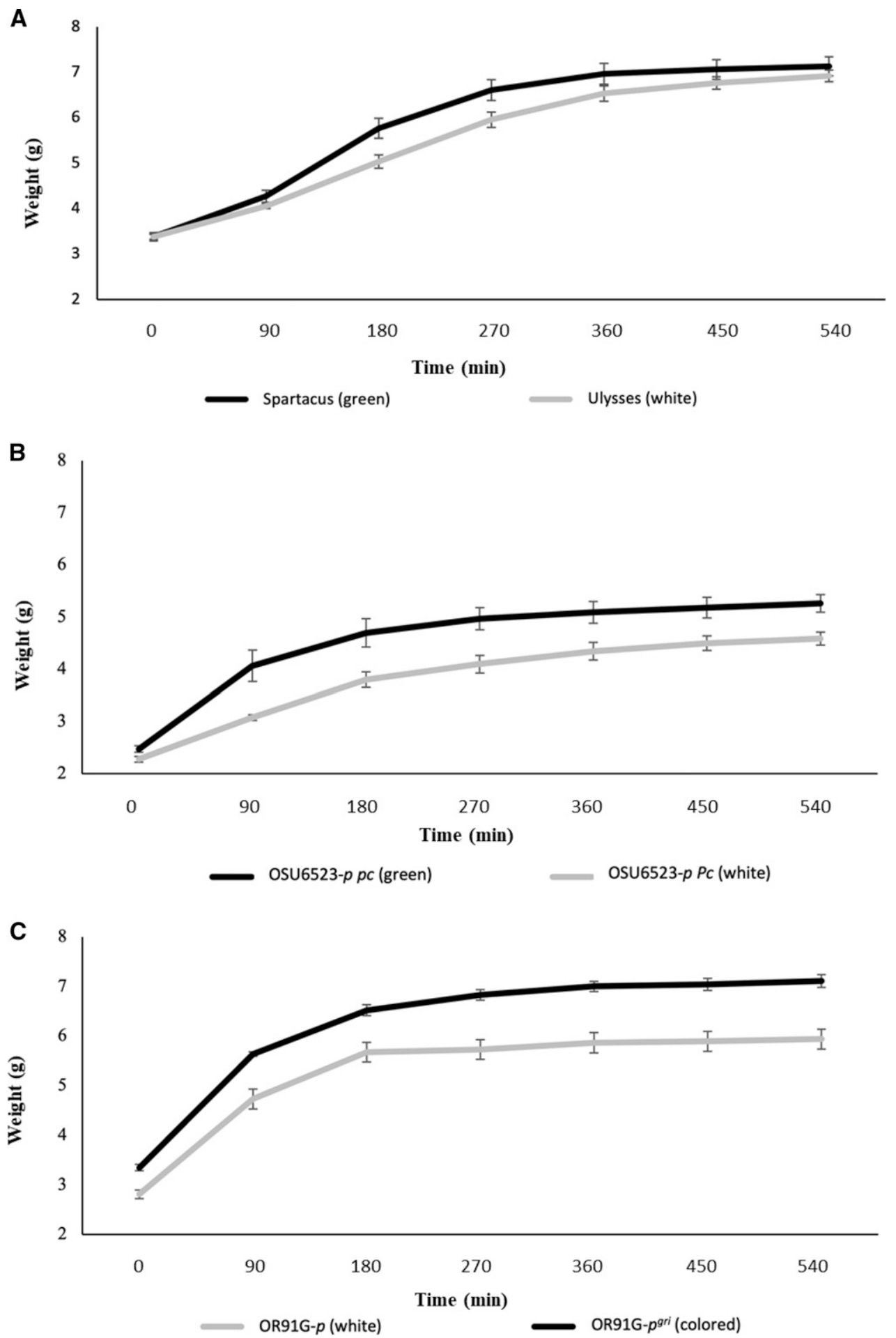

Fig. 2. Comparison of snap bean seeds for water uptake over a 540-minute time period. Error bars represent SE. Weights are reported for 10 seeds per genotype. Comparison of (A) 'Spartacus' ( $p$ pc, green seeded) and 'Ulysses' ( $p$ Pc, white-seeded) snap bean sister lines, (B) 'OSU6523- $p p c$ ' (green-seeded) and 'OSU6523- $p$ $P c^{\prime}$ ' (white-seeded) snap bean near-isogenic lines, and (C) 'OR91G- $p P c$ ' (white-seeded) and 'OR91G- $p^{\text {gri }} P c^{\prime}$ ' (colored-seeded) near isogenic lines. $p$, plant parts not pigmented; $p c$, leaves and stems remain green at senescence, and dry seeds are pale green and cotyledons of emerging seedlings are bleached white; $P c$, plant parts show normal expression; $p^{g r i}$, attenuated pigment expressed.

implies that solutes at threshold levels to trigger pathogen spore germination are present earlier in the surrounding spermosphere compared with other seed types. Our anatomic studies demonstrated that $p c$ seeds have thinner testa compared with other seed types (Figs. 5-7). A thinner testa could account for all the physical properties we observed. A thinner testa is probably more permeable and could allow more solute leakage, which would begin at an earlier time point in the germination process. A thinner testa also allows more rapid water uptake and could be more prone to cracking. In soybean [Glycine max (L.) Merr.], a negative correlation was observed between seedcoat thickness and amount of seedcoat cracking (Yasue and Kinomura, 1984).

Our model of how germination and field emergence are affected adversely in $p c$ types begins with a thinner, more fragile testa, potentially with increased cracking from mechanical damage if care is not taken during seed harvest, conditioning, and handling. A thinner testa, even if undamaged, may allow for more rapid water uptake during germination. Rapid water uptake has been shown to create especially damaging physical stress in snap bean seeds because of their long and cylindrical shape compared with dry edible bean seed (Spaeth, 1986). This leads to imbibitional cracking of not only the testa, but also may damage the embryo and cotyledons as well. Rapid imbibition causing cell damage to the embryo as well as the testa, which reduces germination, has been reported previously (Bewley and Black, 1978; Hahalis et al., 1996; Larson, 1968; Powell and Matthews, 1978). The loss of testa integrity and potential damage to the embryo leads to earlier and increased solute leakage into the surrounding spermosphere, which stimulates pathogen spore germination and chemotaxis in the spermosphere. Poor seed integrity allows pathogens to colonize the germinating seeds at an earlier stage of development, which overwhelms the seed before seedlings can become established.

We did not determine whether a thinner testa in $p c$ types increases solute leakage even when intact, or whether increased cracking induced by more rapid water uptake is the primary issue. Even with a thinner testa, we would expect intact $p c$ seeds to have a more controlled diffusion of solutes 


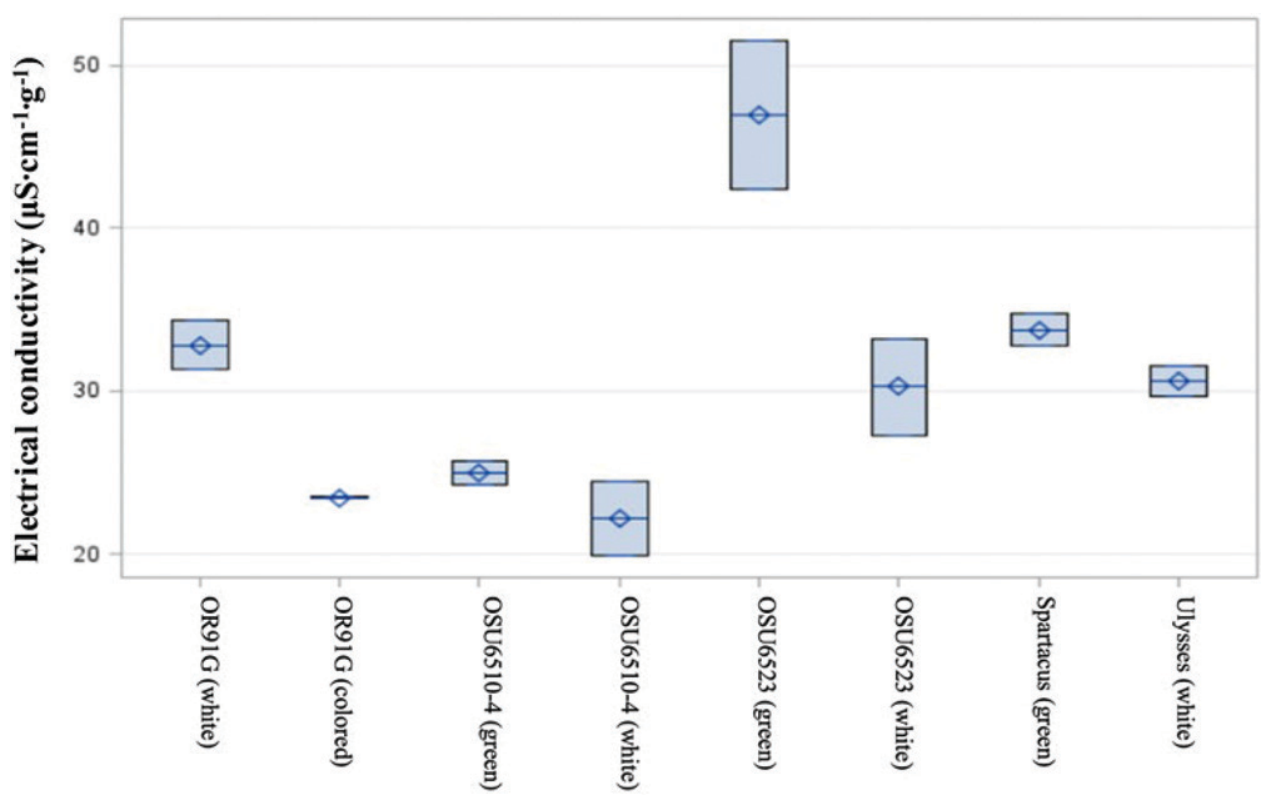

Fig. 3. Box-and-whisker plots for seed solute electrical conductivity on an individual genotype basis for a set of paired snap bean genotypes. The 'OR91G' pair is isogenic for $p$ (white) $p^{\text {gri }}$ (colored) seed. The others are isogenic at the $p c$ locus, with those labeled "green" having the genotype $p p p c p c$ and those labeled "white" as being $p p$ P P Pc. 'Spartacus' is $p p p c p c$ and 'Ulysses' is $p p P c P c$. compared with the catastrophic release when the testa integrity is breached. Testa rupture, rather than increased permeability, is likely to be more important in explaining the deleterious effects on germination and emergence.

The testa has an important role in regulating the imbibition rate and affects susceptibility to injuries and subsequent germinability (Taylor et al., 1992). Imbibition may be modulated by testa thickness or by its physical structure (Powell and Matthews, 1978; Powell et al., 1986a, 1986b). A positive relationship between the percentage of seedcoat damage and hydration rate was reported by Powell and Matthews (1979) and Wolk (1989), and indicated there is reduction in germination rate with increased hydration rate in snap beans. These outcomes are compatible with observations from our water uptake analysis, in
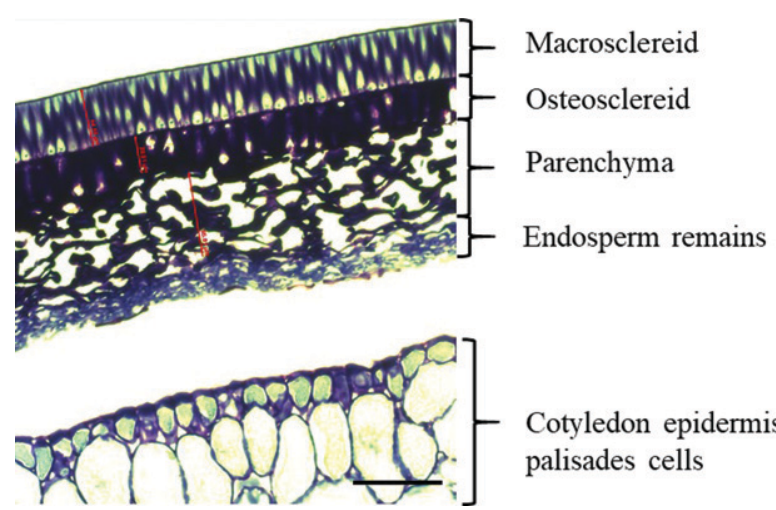

Cotyledon epidermis and palisades cells

Fig. 4. Transversal section of the seedcoat of 'OSU6510-p pc' snap bean showing the three layers of the testa and outer layers of the cotyledon. For the testa layers, top $=$ outer macrosclereid layer, middle $=$ osteosclereids forming the hypodermal layer, bottom = inner parenchyma layer. Endosperm remnants and cotyledon cell layers also are visible; bar $=100 \mu \mathrm{m}$.

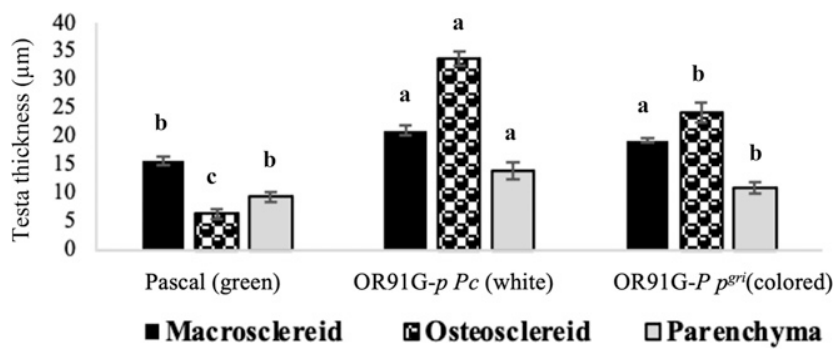

Fig. 5. Thickness of seed testa layers of 'Pascal' dry bean ( $p p c$ ) (greenseeded), 'OR91G- $p P c$ ' (white-seeded), and 'OR91G- $p^{g r i} P c^{\prime}$ ' (coloredseeded) snap bean lines. Error bars represent SE. Within a testa layer, bars with the same letter are not significantly different at $P \leq 0.05$ as determined by Fisher's protected least significant difference.

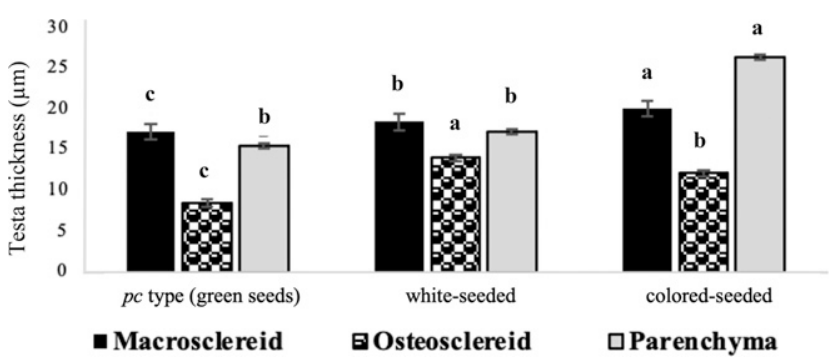

Fig. 6. Thickness of outer seed testa layers of green-seeded ( $p c)$, white-seeded $(p)$ and colored-seeded types for nine snap bean lines ['Pascal' $(p p c)$, 'OR91G- $p P c^{\prime}$ '-'OR91G- $p^{g r i} P c^{\prime}$ ' pair, 'OSU6523- $p$ pc'-'OSU6523- $p P c$ ' pair, 'OSU6510-4- $p$ pc'-'OSU6510-4- $p$ Pc' pair, and 'Spartacus'

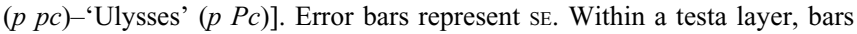
with the same letter are not significantly different at $P \leq 0.05$ as determined by Fisher's protected least significant difference.

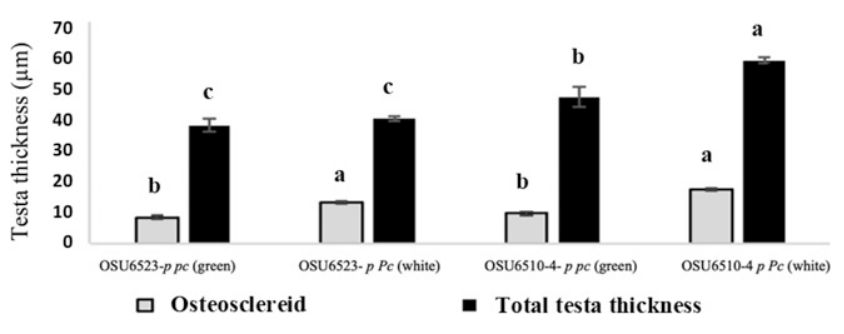

Fig. 7. Osteosclereid and total testa thickness (sum of three outer testa layers) of two snap bean pairs ('OSU6523' and 'OSU6510-4') near-isogenic for green $(p p c)$ and white $(p P c)$ seed. Error bars represent SE. Within a testa layer, bars with the same letter are not significantly different at $P \leq 0.05$ as determined by Fisher's protected least significant difference.

which $p c$ seeds had more rapid water uptake and greater damage.

Although the testa is implicated in modulation of water movement in and out of the seed, other structures may be 
important. Impervious palisade cells (macrosclereids), a prominent light line of the palisade cells, thickened testa, lack of pits, presence of endocarp deposits, dark seed color, closed hilum and/or micropyle, presence of water gaps in the lens, and cracks in the seedcoat cuticle have all been associated with differences between hard and soft seed in terms of water permeability (Smýkal et al., 2014). In general, impermeable seedcoats were associated with closed hilum and/or micropyle anatomy (Ballard, 1973; Hyde, 1954; Rolston, 1978).

The osteosclereid layer is similar in appearance to the macrosclereid layer, but cells are larger, with thicker walls and an hourglass shape, and conspicuous air-filled intercellular spaces. The osteosclereid layer may possibly be related to imbibition and solute movement via its unusual cell structure and organization. Luan et al. (2017) found that the osteosclereid layer could regulate imbibition in soybean, with the outer surface of cells being hydrophobic whereas the inner surface was hydrophilic. The third layer located beneath the osteosclereid layer is the parenchyma layer, which lies next to the transitory endosperm and is thought to be involved in embryo nutrition and development (Smýkal et al., 2014).

The tetrazolium test revealed that the 'OSU6523- $p p c$ ' genotype had a tendency toward hard seeds, although this was not observed in an additional replication. Also, this phenomenon was not observed in the 'OSU6523- $p$ Pc' genotype of the isogenic pair. This is an interesting finding that suggests the hardseed phenomenon is not necessarily related to the testa, because that layer is affected so profoundly in $p c$ types. Our results suggest that differences in nontesta structures such as the hilum, micropyle, and lens are more important than the testa in determining a hard-seed reaction in $p c$ types.

Phenolic acids, their polyphenolic derivatives, and flavonoids are often found in the testa and have both positive and negative interactions with the microbiota in the spermosphere (Nelson, 2004). These compounds are water soluble and are some of the first of the solutes that enter the spermosphere. In our study, we did not expect these compounds to play a role except in the case of the colored-seeded genotypes ('OR91G- $p^{\text {gri }} P c$ ' and 'Roc d'Or'). White seeds conditioned by $p$ lack phenolics and flavonoids, and both white and green $(p c)$ seeds are homozygous recessive at the $p$ locus.

Based on our EC analysis, elevated levels of leaking solutes were observed for $p c$ seeds. The comparisons of isogenic pairs were consistent in that the $p c$ lines always had a greater EC than their white-seeded counterparts. One curious point is that, comparing the plot distributions of 'OSU6510-4' and 'OR91G' (Fig. 3), the 'OSU6510-4' isogenic pair had an overall lower EC compared with the 'OR91G' pair, although the latter had a better percentage of emergence in the field. This may be related seed shape and/or size, as 'OSU6510-4' has flat and slightly smaller seed than the 'OR91G' genotypes. Paul and Ramaswamy (1979) found a positive correlation between increasing seed size and increasing EC from leachate in cowpea [Vigna unguiculata (L.) Walp.]. Another aspect is that even if there is a higher solute leakage from 'OR91G- $p^{g r i} P c^{\prime}$ ' (colored-seeded), flavonoids and other watersoluble phenolics may inhibit microbial growth (Cowan, 1999). In addition, timing of solute leakage may be a factor. If $p c$ types leak solutes into the spermosphere more rapidly, they may receive earlier pathogen colonization even though the overall levels of solutes are lower.
We did not investigate the composition of solutes from germinating seeds, and this is an area for further research. Solutes diffusing from the seed into the spermosphere contain carbohydrates (mainly sugars), organic acids, alcohols, fatty acids, amino acids, proteins, secondary metabolites such as flavonoids and polyphenols, inorganic ions, and various volatiles (Norton and Harman, 1985; Schiltz et al., 2015). Nitrogenous amino acids derived from proteins as well as acetaldehyde and ethanol volatiles have been shown to trigger pathogen spore germination in the spermosphere, and to facilitate hyphal growth and chemotaxis of zoospores toward germinating seeds (Nelson, 2004; Norton and Harman, 1985; Sterner and Elser, 2002). A potential nitrogen source in $p c$ bean seeds could come from the degradation of compounds that would otherwise be destined for chloroplast assembly. Cotyledons of normal seeds have proplastids that, upon germination, quickly assemble thylakoid stacks to begin the process of photosynthesis (Liang et al., 2018). Normal cotyledons are green even after a short period of imbibition and before they are exposed to light; but, although $p c$ seeds are pale green before imbibition, they quickly bleach to a white color. It is not known what the nitrogen content of the proplastids in cotyledons is, but chloroplasts in leaves hold about threequarters of the nitrogen found in the vegetative portions of a plant (Myers et al., 2018). Chlorophyll biosynthesis and catabolism are usually orderly processes because some intermediates are strongly reactive and may damage other cellular reactions if not compartmentalized. The bleaching in $p c$ cotyledons may be symptomatic of a disorderly process and may result in cell injury as well as an uncontrolled release of nitrogenous compounds. The bleaching process might also affect starch-to-sugar conversion during germination because chloroplasts accumulate substantial stores of starch during biosynthesis.

Traditionally, the agricultural industry has used cultural practices to compensate for the poor germination of snap beans, and this same technology has been applied to $p c$ beans. There may be room for further modification of them to accommodate the specific requirements of $p c$ beans. Processes for harvesting and conditioning seeds could be altered to minimize damage even more than is currently done for snap beans. Harvesting the seeds at $\approx 12 \%$ moisture content is important for reducing mechanical injury (Dickson and Boettger, 1976; Taylor and Dickson, 1987). This can be a problem in the intermountain region of the Pacific Northwest, where most snap bean seed is produced because low humidity may cause seed moisture to drop into the single digits at harvest. Some growers with particularly sensitive cultivars may wait until evening to combine seed, when humidity shows a diurnal increase. Storage conditions are another issue associated with seed moisture content and seed quality. For instance, using cold airflow cabinets at $20{ }^{\circ} \mathrm{C}$ and $35 \%$ relative humidity will keep the seed at an optimum moisture content (Salcedo, 2008), but implementing these conditions on a commercial scale is expensive. Reducing seed cracking during the water imbibition could be accomplished by pre-irrigating the field before planting so that the seeds will not be "watered up" in dry soil. Rapid influx of water during imbibition is particularly damaging to seeds compared with more gradual imbibition in an already moist soil. Another potential solution to reducing rate of water uptake and cracking could be the use of pelleted and/or primed seeds. Currently, coatings on bean seeds are not used commercially, but they might be advantageous with $p c$ types because they can impose a physical barrier to water and oxygen diffusion, and regulate the rate of 
imbibition (Sachs et al., 1981, 1982). A related option is the use of primed or pregerminated seed. Priming of seeds can reduce the exposure duration to field pathogens, thereby improving overall survival rates (Parera and Cantliffe, 1991).

A question yet to be answered is whether all $p c$ cultivars have the deleterious features we documented in our study. It is possible that some $p c$ cultivars have a thicker seedcoat, although in our breeding nurseries, where untreated seeds are typically planted, germination percentages observed over many generations have not revealed any $p c$ lines with improved emergence (J.R. Myers, unpublished observations). Identifying $p c$ lines with thicker seedcoats, or breeding for a thicker testa in a $p c$ background, might also be a way to overcome deleterious properties. The search for thicker seedcoats need not be restricted to $p c$ types. One could find genotypes with thicker seedcoats in other backgrounds, then transfer the trait to create thicker, more durable seedcoats in a $p c$ background. In particular, seed testa thickness in the dry bean flageolet cultivars should be investigated. Interestingly, there are no reports of reduced germination in flageolet beans, although this may be because no one has studied the issue in this type formally.

\section{Literature Cited}

Al-Jadi, M., J.R. Myers, S. Kawai, and L.J. Brewer. 2016. Snap-bean germination rates: A comparison of white, persistent color and colored-seeded lines. Annu. Rep. Bean Improv. Coop. 59:219-220.

Baggett, J.R., W. Frazier, and G. Varseveld. 1981. 'Oregon 91' green bean. HortScience 16:230.

Ballard, L. 1973. Physical barriers to germination. Seed Sci. Technol. 1:285-303.

Bassett, M.J. 2007. Genetics of seed coat color and pattern in common bean. Plant Breed. Rev. 28:239-315, doi: https://doi.org/10.1002/ 9780470168028.ch8.

Bewley, J.D. and M. Black. 1978. Physiology and biochemistry of seeds in relation to germination. Springer, Berlin, Germany.

Bouwkamp, J. and S. Honma. 1970. Physiological differences between a green and a tan dry podded line of snap bean. HortScience 5:171-173.

Cowan, M.M. 1999. Plant products as antimicrobial agents. Clin. Microbiol. Rev. 12:564-582, doi: https://doi.org/10.1128/cmr.12.4.564.

Davis, J., J.R. Myers, P. McClean, and R. Lee. 2009. Staygreen (sgr), a candidate gene for the persistent color phenotype in common bean. Acta Hort. 859:99-102, doi: https://doi.org/10.17660/ActaHortic.2010. 859.10.

Dean, L. 1968. Progress with persistent-green color and green seed coat in snap beans (Phaseolus vulgaris L.) for commercial processing. HortScience 3:177-178.

Dickson, M. and M. Boettger. 1976. Selection for seed quality in white seeded snap bean. Annu. Rep. Bean Improv. Coop. 19:24-25.

Food and Agriculture Organization of the United Nations. 2021. FAOSTAT. 28 Feb. 2021. <http://www.fao.org/faostat/en/\#data/QC>.

Hahalis, D., M. Cochrane, and M. Smith. 1996. Water penetration sites in the testa of soybeans (Glycine max L. Merril) during seed imbibition. Sci. Legumes 3:218-226.

Halloin, J.M. 1986. Seed improvement through genetic resistance to pathogenesis, p. 77-95. In: S.H. West (ed.). Physiological-pathological interactions affecting seed deterioration. Crop Science Society of America special publication no. 12. American Society of Agronomy, Crop Science Society of America, Soil Science Society of America, Madison, WI, doi: https://doi.org/10.2135/cssaspecpub12.c6.

Hyde, E. 1954. The function of the hilum in some Papilionaceae in relation to the ripening of the seed and the permeability of the testa. Ann. Bot. 18:241-256, doi: https://doi.org/10.1093/oxfordjournals. aob.a083393.
International Seed Testing Association. 2005. International rules for seed testing, 2005 ed. International. Seed Testing Association, Bassersdorf, Switzerland.

Larson, L. 1968. The effect soaking pea seeds with or without seedcoats has on seedling growth. Plant Physiol. 43:255-259, doi: https:// doi.org/10.1104/pp.43.2.255.

Liang, Z., N. Zhu, K.K. Mai, Z. Liu, D. Tzeng, K.W. Osteryoung, S. Zhong, L.A. Staehelin, and B.-H. Kang. 2018. Thylakoid-bound polysomes and a dynamin-related protein, FZL, mediate critical stages of the linear chloroplast biogenesis program in greening arabidopsis cotyledons. Plant Cell 30:1476-1495, doi: https://doi.org/10.1105/ tpc.17.00972.

Luan, Z., J. Zhao, D. Shao, D. Zhou, L. Zhang, W. Zheng, and Q. Sun. 2017. A comparison study of permeable and impermeable seed coats of legume seed crops reveals the permeability related structure difference. Pak. J. Bot. 49:1435-1441.

Mauseth, J.D. 1988. Plant anatomy. Benjamin/Cummings, Menlo Park, CA.

Mayne, R., G. Harper, A. Franz, Jr., L. Lee, and L. Goldblatt. 1969. Retardation of the elaboration of aflatoxin in cottonseed by impermeability of the seedcoats. Crop Sci. 9:147-150, doi: https://doi.org/ 10.2135/cropsci1969.0011183X000900020009x.

Miklas, P. 2017. Bean genes list 2018, list of genes_-Phaseolus vulgaris L. 28 Feb. 2021. http://www.bic.uprm.edu/wp-content/uploads/ 2019/10/Bean-Genes-List-2018-v2-1.pdf.

Mohamed-Yasseen, Y. 1991. Onion (Allium cepa L.) seed aging and plant regeneration in vitro. University of Illinois, Urbana-Champaign, PhD Diss.

Mohamed-Yasseen, Y., B.P. Jakstys, and W.E. Splittstoesser. 1991. Methods of onion seed preparation for scanning electron microscope studies of the seed coat. J. Electron Microsc. Tech. 18:207-208.

Mohamed-Yasseen, Y. and W. Splittstoesser. 1991. Scanning electron microscopic studies on onion (Allium cepa L.) seeds and their relation to viability. Interamerican Soc. Trop. Hort. 37:127-132.

Myers, J.R., M. Aljadi, and L. Brewer. 2018. The importance of cosmetic stay-green in specialty crops. Plant Breed. Rev. 42:219-256, doi: https://doi.org/10.1002/9781119521358.ch6.

Myers, J.R. and J.R. Baggett. 1999. Improvement of snap bean, p. 289-329. In: S. Singh (ed.). Common bean improvement in the twenty-first century. Kluwer Academic Publishers, Boston, MA.

Nelson, E.B. 2004. Microbial dynamics and interactions in the spermosphere. Annu. Rev. Phytopathol. 42:271-309, doi: https://doi.org/ 10.1146/annurev.phyto.42.121603.131041.

Norton, J.M. and G. Harman. 1985. Responses of soil microorganisms to volatile exudates from germinating pea seeds. Can. J. Bot. 63:1040-1045, doi: https://doi.org/10.1139/b85-142.

Parera, C.A. and D.J. Cantliffe. 1991. Improved germination and modified imbibition of shrunken-2 sweet corn by seed disinfection and solid matrix priming. J. Amer. Soc. Hort. Sci. 116:942-945, doi: https://doi.org/10.21273/JASHS.116.6.942.

Patil, V.N. and M. Dadlani. 1993. Tetrazolium test for seed viability and vigour, p. 209-241. In: P.K. Agrawal (ed.). Handbook of seed testing. National Seeds Corporation, New Delhi, India.

Paul, S. and K. Ramaswamy. 1979. Relationship between seed size and seed quality attributes in cowpea (Vigna sinensis L. Savi). Seed Res. 7:63-70.

Powell, A.A. and S. Matthews. 1978. The damaging effect of water on dry pea embryos during imbibition. J. Expt. Bot. 29:1215-1229, doi: https://doi.org/10.1093/jxb/29.5.1215.

Powell, A.A. and S. Matthews. 1979. The influence of testa condition on the imbibition and vigour of pea seeds. J. Expt. Bot. 30:193-197, doi: https://doi.org/10.1093/jxb/30.1.193.

Powell, A.A., M.A. Oliveira, and S. Matthews. 1986a. Seed vigour in cultivars of dwarf French bean (Phaseolus vulgaris) in relation to the colour of the testa. J. Agr. Sci. 106:419-425, doi: https://doi.org/ $10.1017 / \mathrm{S} 0021859600064030$. 
Powell, A.A., M.D.A. Oliveira, and S. Matthews. 1986b. The role of imbibition damage in determining the vigour of white and coloured seed lots of dwarf French beans (Phaseolus vulgaris). J. Expt. Bot. 37:716-722, doi: https://doi.org/10.1093/jxb/37.5.716.

Rolston, M.P. 1978. Water impermeable seed dormancy. Bot. Rev. 44:365-396.

Sachs, M., D. Cantliffe, and T. Nell. 1981. Germination studies of claycoated sweet pepper seeds. J. Amer. Soc. Hort. Sci. 106:385-389.

Sachs, M., D. Cantliffe, and T. Nell. 1982. Germination behavior of sand-coated sweet pepper seed. J. Amer. Soc. Hort. Sci. 107:412-416.

Salcedo, J. 2008. Regeneration guidelines: Common bean, p. 1-9. In: M.E. Dulloo, I. Thormann, M.A. Jorge, and J. Hanson. (eds.). Cropspecific regeneration guidelines. CGIAR System-wide Genetic Resource Programme, Rome, Italy.

Schiltz, S., I. Gaillard, N. Pawlicki-Jullian, B. Thiombiano, F. Mesnard, and E. Gontier. 2015. A review: What is the spermosphere and how can it be studied? J. Appl. Microbiol. 119:1467-1481, doi: https://doi.org/10.1111/jam.12946.

Smýkal, P., V. Vernoud, M.W. Blair, A. Soukup, and R.D. Thompson. 2014. The role of the testa during development and in establishment of dormancy of the legume seed. Front. Plant Sci. 5:351, doi: https:// doi.org/10.3389/fpls.2014.00351.

Spaeth, S. 1986. Imbibitional stress and transverse cracking of bean, pea, and chickpea cotyledons. HortScience 21:110-111.
Splittstoesser, W., Y. Mohamed-Yasseen, and R. Skrivin. 1994. Screening for onion seeds with hard seed coats and propagation in vitro. Proc. Plant Growth Reg. Soc. Amer. 21:273-276.

Sterner, R.W. and J.J. Elser. 2002. Ecological stoichiometry: The biology of elements from molecules to the biosphere. Princeton University Press, Princeton, NJ.

Taylor, A. and M. Dickson. 1987. Seed coat permeability in semi-hard snap bean seeds: Its influence on imbibitional chilling injury. J. Hort. Sci. 62:183-189, doi: https://doi.org/10.1080/14620316.1987.11515768.

Taylor, A., J. Prusinski, H. Hill, and M. Dickson. 1992. Influence of seed hydration on seedling performance. HortTechnology 2:336-344, doi: https://doi.org/10.21273/HORTTECH.2.3.336.

Thomas, H. and C.J. Howarth. 2000. Five ways to stay green. J. Expt. Bot. 51:329-337, doi: https://doi.org/10.1093/jexbot/51.suppl_1.329.

Thomas, H. and C.M. Smart. 1993. Crops that stay green. Ann. Appl. Biol. 123:193-219, doi: https://doi.org/10.1111/j.1744-7348.1993.tb04086.x.

U.S. Department of Agriculture, National Agricultural Statistics Service. 2020. Statistics by subject. 28 Feb. 2021. <https://www.nass. usda.gov/Statistics_by_Subject/index.php?sector=CROPS $>$.

Wolk, W.D. 1989. Imbibitional injury of Phaseolus vulgaris, L. seeds. Michigan State University, East Lansing, PhD Diss.

Yasue, T. and N. Kinomura. 1984. Studies on the mechanism of seedcoat cracking and its prevention in soybeans: I. Regional and varietal difference in cracking of seedcoat in soybeans. Jpn. J. Crop. Sci. 53:87-93. 
Supplemental Table 1. Snap bean breeding lines and cultivars that were increased at the Oregon State University Vegetable Research Farm, Corvallis, OR, in 2017 and subsequently used to characterize persistent color types.

\begin{tabular}{|c|c|c|c|c|c|}
\hline Accession & Seed phenotype & Seed genotype ${ }^{z}$ & Accession & Seed phenotype & Seed genotype \\
\hline Booster & White & $p P c$ & OSU6510-4- $p p c$ & Green & $p p c$ \\
\hline Bush Romano & Green & $p p c$ & OSU6510-4- $p P c$ & White & $p P c$ \\
\hline Castano & Green & $p p c$ & OSU6512 & Green & $p p c$ \\
\hline Clyde & White & $p P c$ & OSU6523- $p p c$ & Green & $p p c$ \\
\hline Cruiser & White & $p P_{c}$ & OSU6523- $p P c$ & White & $p P c$ \\
\hline Embassy & Green & $p p c$ & OSU6562-2 & Green & $p p c$ \\
\hline Flamata- $p p c$ & Green & $p p c$ & OSU6929 & Green & $p p c$ \\
\hline Flamata- $p P c$ & White & $p P c$ & OSU7025 & White & $p P c$ \\
\hline Flaveol & Green & $p p c$ & Ovation & White & $p P c$ \\
\hline Freshpick & Green & $p p c$ & Pascal & Green & $p p c$ \\
\hline Hercules & Green & $p p c$ & Profit & White & $p P c$ \\
\hline Hystyle & Green & $p p c$ & Quest & Green & $p p c$ \\
\hline OR91g-2-1-djv & Colored & $p P c d j v$ & Tempest- $p p c$ & Green & $p p c$ \\
\hline OR91g-2-2-djv & Colored & $p P c d j v$ & Tempest- $p P c$ & White & $p P c$ \\
\hline OR91G- $p^{g r i} P c$ & Colored & $p^{g r i} P c$ & Titan & Green & $p p c$ \\
\hline OSU6504- $p p c$ & Green & $p p c$ & Ulysses & White & $p P c$ \\
\hline OSU6504- $p P c$ & White & $p P c$ & - & - & - \\
\hline
\end{tabular}

${ }^{\mathrm{z}}$ Genotype description. Pigment: with $P$, seeds, flowers, and other plant parts pigmented depending on what other genes are expressed; $p^{g r i}=$ attenuated pigment expressed; $p=$ plant parts not pigmented. Persistent color: with $P c$, plant parts show normal expression; $p c=$ leaves and stems remain green at senescence; dry seeds are pale green and cotyledons of emerging seedlings are bleached white. $C$ : color and pattern regulator in seeds; $c^{u}=$ unchangeable cartridge buff seed color. $D$, hilum ring factor, with $D$ and $J$, hilum ring present; $d$ with $j$, hilum ring absent. $d$ is now named $z$. Joker: with $J$, dark seed colors, after darkening with age; $j=$ pale colors not after darkening. Violet: with $V$ violet to black seed color and purple flowers; $v=$ brown seeds and white flowers. The interaction of $d j$ and $v$ produces a near-white seed color. Descriptions from Bean Genes List 2018 (Miklas, 2017). 